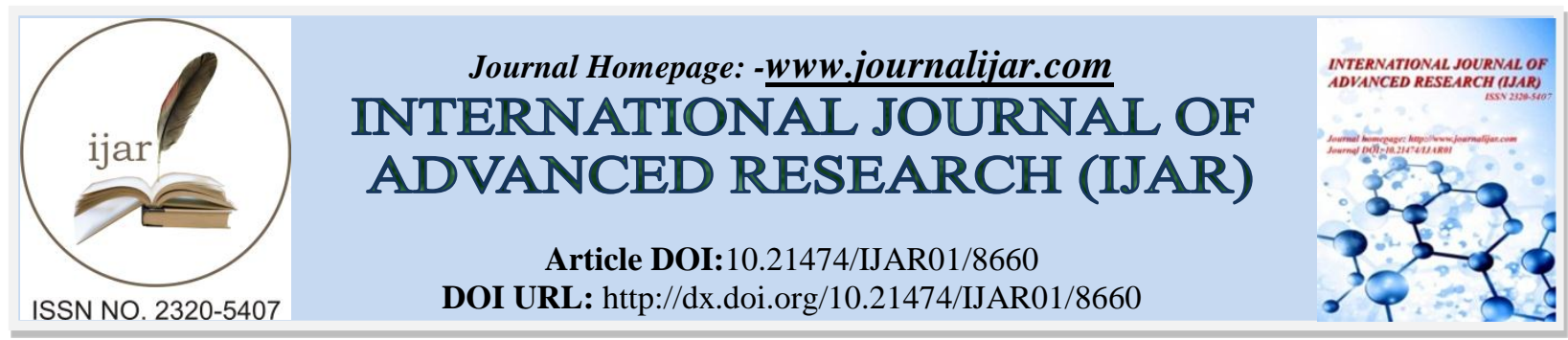

RESEARCH ARTICLE

\title{
CULTURAL AND RELIGIOUS FACTORS AS PREDICTORS OF UPTAKE OF SKILLED BIRTH SERVICES IN LURAMBI SUB COUNTY, KENYA - A CROSS SECTIONAL STUDY.
}

Beatrice Mukabana ${ }^{1}$ and Victor Mukaka Emali ${ }^{2}$.

1. Department or Reproductive Heaalth, Midwifery, Child Health and Medical Social Work, Masinde Muliro University.

2. Department of Clinical nursing and health informatics, Masinde Muliro University of science and technology.

\section{Manuscript Info}

\section{Manuscript History}

Received: 09 January 2018

Final Accepted: 11 February 2019

Published: March 2019

Key words:-

ANC, skilled birth delivery, Kakamega county, cultural factors, religious factors, nursing.

\section{Abstract}

Introduction: Ensuring all women give birth with the help of a skilled birth attendant and access to emergency obstetric care is accepted as the most crucial intervention for reducing maternal and newborn deaths. However, this has failed as only $70 \%$ of women utilize skilled attendance globally and only $61 \%$ in Kenya

Objective. To determine the influence of cultural and religious factors on uptake of skilled birth services in Lurambi sub-County.

Methods: Cross-sectional study and Quantitative methods were adopted. Carried out in Kakamega County with a Sampling frame consisting of all the 17 government facilities. A multistage stratified sampling strategy was used and Probability sampling technique of systematic sampling method was applied to select women seeking health facility delivery services in Lurambi sub county government facilities $(n=200)$. Data was analyzed through descriptive statistics, chi-square and logistic regression.

Results: Majority of the women were aged 20-35 years (70.5\%), 66\% were married, $40 \%$ had 1-2 children and majority had attained secondary education at $48.5 \%$ as the highest educational level. Many were from other ethnic origin at $44.5 \%$, followed by Watsotso at $31.5 \%$ and the least population are Waidakho at 24\%. Majority of the women were Christians at $97.5 \%$ and only $2.5 \%$ were Muslims. Majority of the women had ever used family planning methods at $61.5 \%$ (123) and only $38.5 \%$ (77) had never used family planning method. Families believed that deliveries should be conducted at a health facility at $84 \%$ (168), 12\% (24) believed that delivery must be conducted in a new homestead and only $2.5 \%$ (5) believed that they should never be assisted to deliver by a man. Majority of the women's culture or religion dictates that delivery be done in a health facility at $97.5 \%$ and only $2.5 \%$ dictates it to be done at home environment. Women who perceived that health facility delivery was dictated by culture and religion were $60 \%$ less likely to receive optimal skilled birth service unlike their colleagues who thought otherwise (OR: 0.4 ; 95\% CI: 0.2 $0.9 ; \mathrm{p}=0.02)$.

Conclusion and Recommendation: Culture and religion are less likely associated with determination of use of skilled birth services. Antenatal

Corresponding Author:-Beatrice Mukabana.

Address:-Department or Reproductive Heaalth, Midwifery, Child Health and Medical Social Work, 
clinic uptake interventions should target male partner buy-in and support, healthcare provider training to improve attitudes.

Copy Right, IJAR, 2019,. All rights reserved.

\section{Introduction:-}

Globally utilization of skilled birth attendance is at 70\%, in Africa it is at 50\% (WHO, 2014). While in Kenya it is at $61 \%$ (KDHS, 2014). Sustainable Development Goal 3 is to improve maternal health remains global health challenge. Ensuring all women give birth with the help of a skilled birth attendant and access to emergency obstetric care is accepted as the most crucial intervention for reducing maternal and newborn deaths (Dzakpasu, PowelJackson, \& Campbel, 2013). Factors determining maternity services utilization are diverse and yet interrelated. The factors can be grouped into five main factors namely socio-cultural factors, Physical access, and economic access, past obstetric experience and perceived benefit or quality of care. Individual factors however are also shaped by other broader factors, often beyond the immediate control of the individual or community (Bourbonnais, 2013).

Several determinants of skilled delivery have been examined and while analyzing the 2008/2009 Kenya DHS demonstrated that living in urban areas, being wealthy, more educated, using antenatal care services optimally and lower parity strongly predicted where women delivered and so did region, ethnicity and type of infrastructure used (Kitui et al.,2013). Several studies have examined the uptake of skilled delivery care, one important inference from existing literature is thus influences of individual and household level factors on the uptake of such services vary across geographic and social settings. However, the studies in question focused on individual level factors forgetting influences contextual factors exert on the uptake of health care services. The downside is that this underestimates the importance of taking contextual factors into account when planning appropriate interventions in promoting safe motherhood in the country (Kitui, et al., 2013).

In recent years, studies have also found that contextual factors are key determinants of maternal health service utilization. The argument put forward is that persons with similar socio-economic characteristics may have different health seeking behavior depending on whether they live in one community or another and therefore the contextual phenomena that cluster individual health seeking behavior within communities has become a core notion of social epidemiology literature (Markos, et al, 2017).

\section{Cultural and religious factors}

Factors determining maternity services utilization are diverse and yet interrelated. The factors can be grouped into five main factors namely socio-cultural factors, Physical access, and economic access, past obstetric experience and perceived benefit or quality of care. Individual factors however are also shaped by other broader factors, often beyond the immediate control of the individual or community (Bourbonnais, 2013). These individual factors include, education, household factors including family size and household wealth, marital status, parity, maternal age and community and environmental factors. Others include region, community health infrastructure, available health facilities and distance to health facilities. These factors have been identified to operate in diverse contexts to determine place of delivery (Esena \& Sappor, 2013).

Kitui et al. analyzing the 2008/2009 Kenya DHS demonstrated that living in urban areas, being wealthy, more educated, using antenatal care services optimally and lower parity strongly predicted where women delivered. Other factors noted were region, ethnicity and type of infrastructure used. In Ghana, a recent study by Amoakoh-Coleman et al. using the 2008 Ghana demographic health survey to identify the demographic, maternal and community determinants of skilled attendance at birth by women who attend at least one ANC during their term of pregnancy found that factors such as religion, health insurance coverage, wealth status, residency, complications with previous pregnancy, and to be significant predictors of skilled attendance at delivery (Esena \& Sappor, 2013). Many women in many communities in the African sub-region lack the decision-making capacity to choose where to deliver and that this decision usually rests on the household head (mostly the husband), especially if such a decision would have some element of cost attached (Esena \& Sappor, 2013).

Poor maternal health service utilization indicators in sub-Saharan Africa (SSA) have been linked to women's socioeconomic dependency on men, and unequal gender relations arising from religious and cultural influences (UNAIDS, 2014 and Ganle,2015). Spirituality and faith-based practices play an integral role in coping with psychological difficulties in illness and in health-seeking behaviors (Hussen et al, 2014). The influence of Religion 
can therefore inform some of the differences in uptake of available healthcare services within or between some populations.

To encourage utilization of available maternal health services, important strategies to consider include advocating to and educating male partners on the importance of supporting access to and payment for facility-based maternal services without undermining their traditional decision-making roles. Where necessary, alternate family members should be nominated to facilitate pregnant women's attendance at facility appointments or deliveries if a husband was unavailable. In addition, healthcare providers especially in rural areas should be made aware of the impact of negative or disrespectful attitudes to the success of ANC (Al-Mujtaba et al., 2016). Other possible barriers include lack of confidence in healthcare facilities, financial cost of healthcare, domestic workload, and traditional practices that include a preference for birthing at home under the supervision of a traditional birth attendant (King, et al., 2015).

The community's beliefs and practices including religion play a crucial role as critical determinants of use of maternal health services. Accessibility of health services has been shown to be an important determinant of utilization of health services in developing countries (Muckle, Sprague, \& Fergus, 2013). The broad objective of the study was to determine predictors of uptake of skilled birth services in Lurambi sub-County. The specific objectives were to determine if cultural and religious factors influence uptake of skilled birth services and to analyze health facility related factors that affect uptake of skilled birth services in Lurambi sub-County. The findings will be utilized for planning and implementation of programs to improve uptake of skilled birth services in Lurambi subCounty.

\section{Methods:-}

The study was conducted in Kakamega county and ethics approval was obtained from Masinde Muliro University of Science and Technology ethics board..

\section{Research Design:}

Study design was quantitative design whereby the cross-sectional design was used due to time factor available for the study to be conducted hence requiring data to be collected in a point in time and secondly it was to facilitate the collection of original data necessary to realize the research objectives, and lastly it was appropriate in collecting useful data that was quantified and reported as a representation of the real situation or characteristic in the study population. Descriptive study design was ideal as the study was carried out in a limited geographical scope and hence it was logistically easier and simpler to conduct considering the limitations of this study (Mugenda\& Mugenda, 2008).

\section{Study setting and Participants}

Sampling frame consisting of all the 17 government facilities were used. A multistage stratified sampling strategy was used, since the facilities are not homogenous in terms of services offered. They were grouped into three strata which are homogenous in themselves i.e. those offering comprehensive emergency obstetric and neonatal care (CEmONC), those offering basic emergency obstetric and neonatal care (BEmONC) as health centres and as dispensaries. At each of the drawn facilities, three departments. MCH/FP, labour ward and maternity will be put into consideration and sample apportioned equally to the three departments as follows.

Table 1:-Sampling frame

\begin{tabular}{|l|l|l|l|}
\hline STRATA & $\begin{array}{l}\text { NUMBER OF } \\
\text { FACILITIES }\end{array}$ & SAMPLE SIZE & $\begin{array}{l}\text { SAMPLE SIZE PER } \\
\text { FACILITY }\end{array}$ \\
\hline CEmONC- 50\% & 1 & 103 & 103 \\
\hline BEmONC-Health centres-30\% & 2 & 62 & 31 \\
\hline BEmONC-Dispensaries-20\% & 14 & 41 & 3 \\
\hline Total & 17 & 206 & \\
\hline
\end{tabular}

complications with previous pregnancy, complications with previous pregnancy,

Table 2:-Demographic Information

\begin{tabular}{|l|l|c|c|}
\hline Variable & Categories & n & $\%$ \\
\hline Age groups (in years) & $\mathbf{1 0}-\mathbf{1 4}$ & 5 & 2.5 \\
\hline
\end{tabular}




\begin{tabular}{|l|l|c|c|}
\hline \multirow{5}{*}{ Marital status } & $\mathbf{2 5}-\mathbf{3 4}$ & 32 & 16 \\
\cline { 2 - 4 } & $\mathbf{3 5}-\mathbf{4 4}$ & 141 & 10.5 \\
\cline { 2 - 4 } & $\mathbf{4 5}$ & 22 & 18.5 \\
\cline { 2 - 4 } & Single & 37 & 66 \\
\cline { 2 - 4 } & Married & 132 & 1.5 \\
\cline { 2 - 4 } & Divorced & 3 & 7.5 \\
\cline { 2 - 4 } & Widow & 15 & 6.5 \\
\cline { 2 - 4 } & Separated & 13 & 1.0 \\
\hline \multirow{5}{*}{ No. of children of education } & None & 2 & 24.5 \\
\cline { 2 - 4 } & Primary & 49 & 48.5 \\
\cline { 2 - 4 } & Secondary & 97 & 26 \\
\cline { 2 - 4 } & Tertiary & 52 & 40 \\
\cline { 2 - 4 } & One to two & 80 & 33 \\
\cline { 2 - 4 } & Three to four & 66 & 22.5 \\
\cline { 2 - 4 } & Five to six & 45 & 4.5 \\
\cline { 2 - 4 } & Seven and above & 9 & \\
\hline
\end{tabular}

It can be deduced from the above table that majority of the women are aged $20-35 \%$ (70.5\%), are married (66\%), have 1-2 children (40\%) and majority have attained secondary education at $48.5 \%$ as the highest educational level.

\section{Cultural and religious factors}

Figure 1 reveals that Lurambi sub county is a cosmopolitan area where majority are from other ethnic origin at $44.5 \%$, followed by Watsotso at $31.5 \%$ and the least population are Waidakho at $24 \%$. Majority of the women were of Christian origin at $97.5 \%$ and only $2.5 \%$ were Muslims as revealed in figure 2. Figure 3 reveals that majority of the women had ever used family planning methods at $61.5 \%$ (123) and only $38.5 \%$ (77) had never used family planning method. From figure 4 majority of the families believed that deliveries should be conducted at a health facility at $84 \%$ (168). This was followed by belief that delivery must be conducted in a new homestead at $12 \%$ (24) and that they should never be assisted to deliver by a man at $2.5 \%$ (5). However, a small number of women believed that all deliveries must be conducted at home at 1.5\% (3). Figure 5 reveals that majority of the women's culture or religion dictated that delivery be done in a health facility at $97.5 \%$ and only $2.5 \%$ dictated that it should be done at home environment.

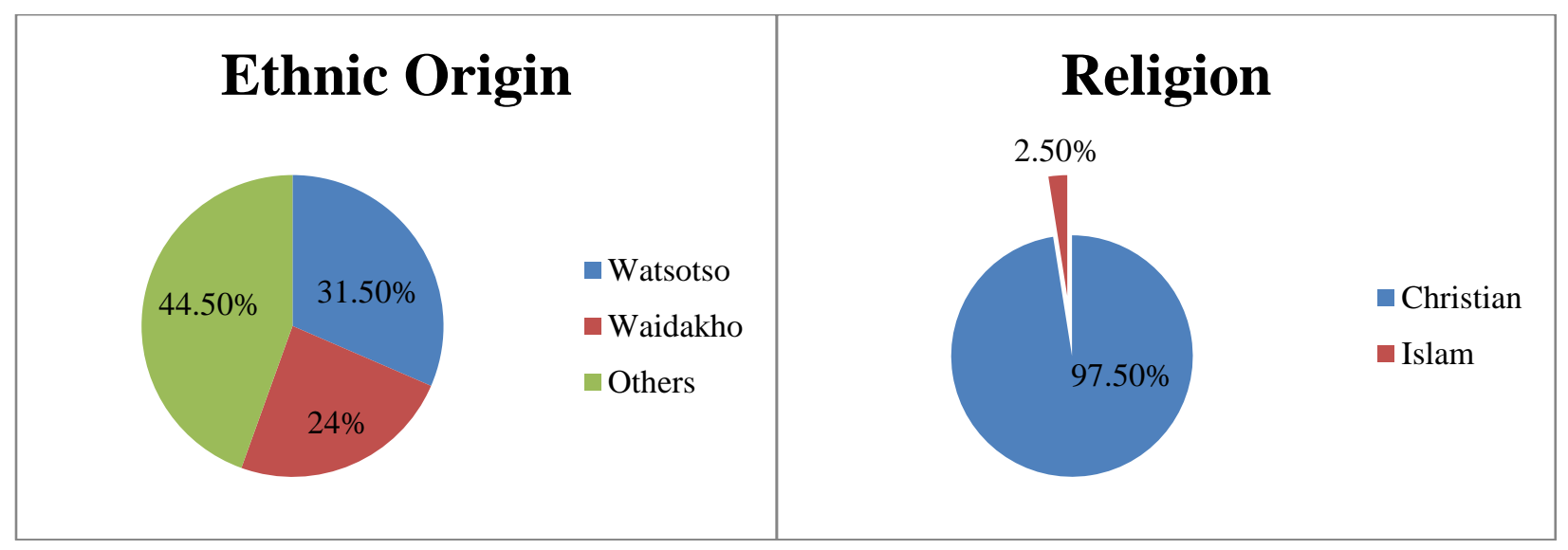

Figure 1:-Ethnic Origin

Figure 2:-Religion 


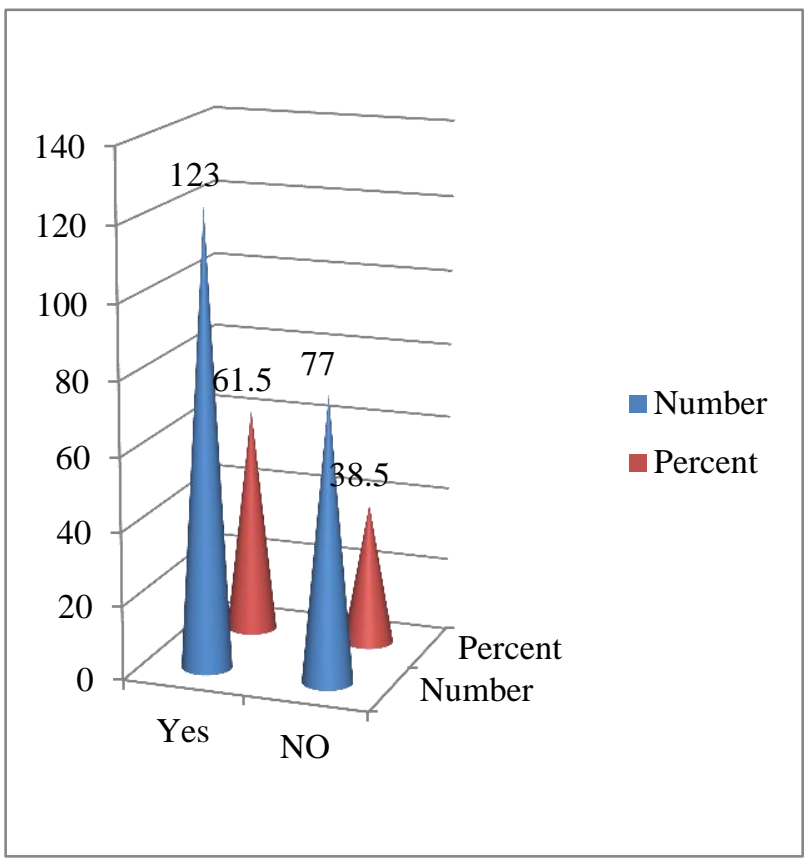

Figure 3:-Ever used family planning before

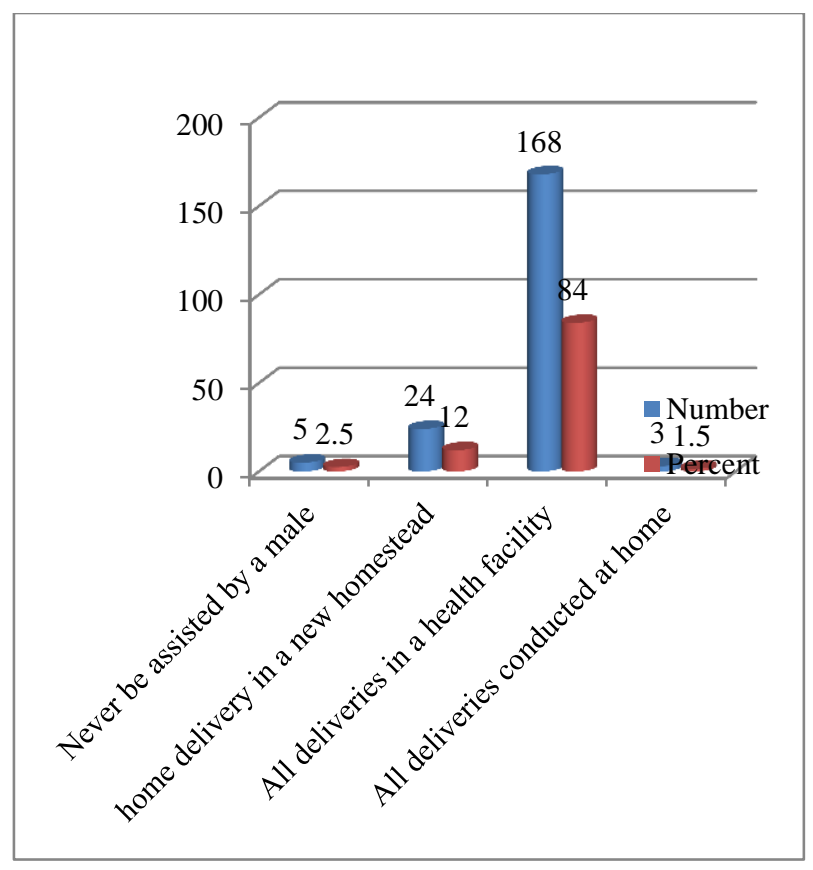

Figure 1:-Culture in relation to delivery

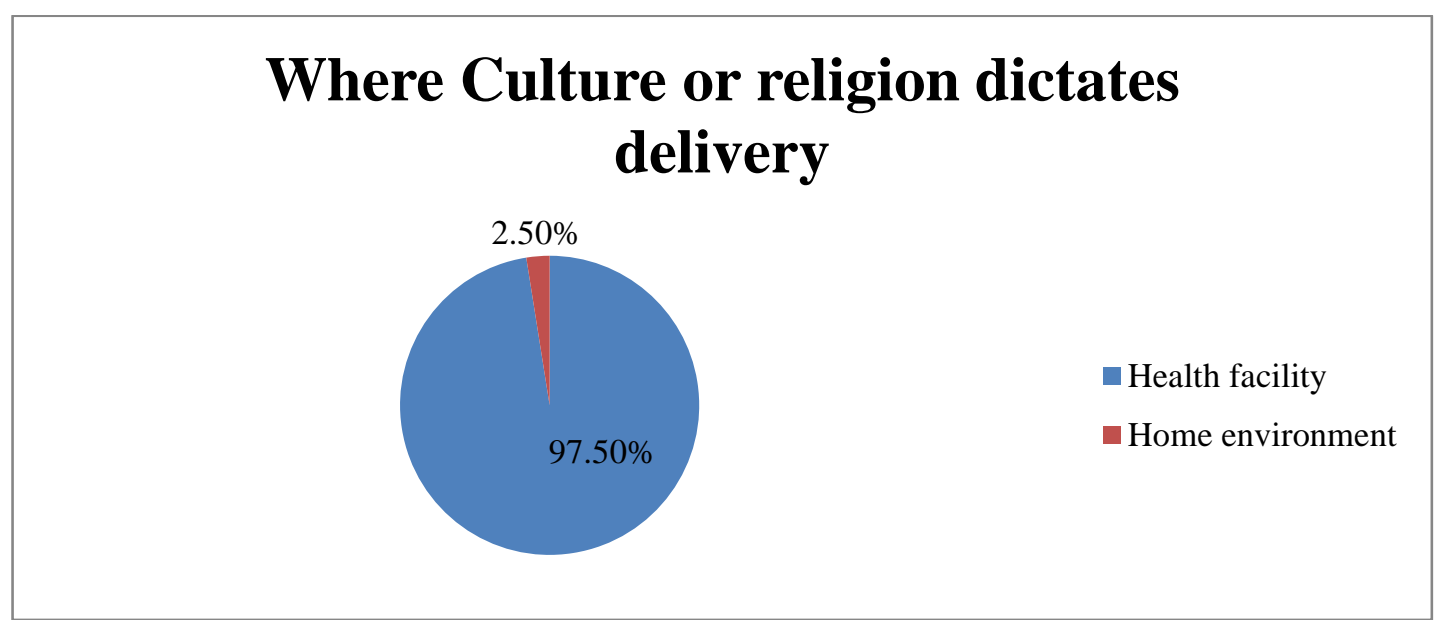

Figure 2:-Where Culture or Religion dictates delivery

Bivariate analysis of the relationship between individual factors and uptake of skilled birth service Table 3:-Facility factors associated with uptake of skilled birth service

\begin{tabular}{|c|c|c|c|c|c|c|}
\hline \multirow[t]{2}{*}{ Characteristic } & \multirow[b]{2}{*}{$\mathbf{N}$} & \multicolumn{2}{|c|}{ Skilled birth service } & \multirow[t]{2}{*}{ Overall OR } & \multirow{2}{*}{$\begin{array}{l}95 \% \\
\text { CI }\end{array}$} & \multirow[t]{2}{*}{ p value } \\
\hline & & Good service & Poor services & & & \\
\hline \multicolumn{7}{|l|}{ Ethnic origin } \\
\hline Watsotso & 63 & 54.0 & 46.0 & \multirow[t]{3}{*}{1.0} & \multirow{3}{*}{$\begin{array}{l}0.7 \\
1.4\end{array}$} & \multirow[t]{3}{*}{0.9} \\
\hline Waidakho & 48 & 54.6 & 45.6 & & & \\
\hline Others & 89 & 43.0 & 57.0 & & & \\
\hline \multicolumn{7}{|l|}{ Religion } \\
\hline Christian & 195 & 54.1 & 45.9 & \multirow[t]{2}{*}{1.0} & 0.7 & \multirow[t]{2}{*}{0.99} \\
\hline Islam & 5 & 54.2 & 45.8 & & 1.8 & \\
\hline
\end{tabular}




\begin{tabular}{|c|c|c|c|c|c|c|c|}
\hline \multicolumn{8}{|l|}{ Ever used family planning } \\
\hline Yes & 123 & 54.9 & 45.1 & \multirow[t]{2}{*}{1.1} & \multirow{2}{*}{$\begin{array}{l}0.8 \\
1.5\end{array}$} & - & \multirow[t]{2}{*}{0.7} \\
\hline No & 77 & 53.3 & 46.7 & & & & \\
\hline \multicolumn{8}{|c|}{ Culture in relation to delivery } \\
\hline $\begin{array}{l}\text { Never be assisted by a } \\
\text { male }\end{array}$ & 5 & 54.4 & 45.6 & \multirow[t]{2}{*}{1.0} & \multirow[t]{2}{*}{$\begin{array}{l}0.6 \\
1.4\end{array}$} & \multirow[t]{2}{*}{-} & \multirow[t]{2}{*}{0.9} \\
\hline $\begin{array}{l}\text { Home delivery in a new } \\
\text { homestead }\end{array}$ & 24 & 54.0 & 46.0 & & & & \\
\hline $\begin{array}{l}\text { All deliveries in a health } \\
\text { facility }\end{array}$ & 168 & 54.1 & 45.9 & & & & \\
\hline $\begin{array}{l}\text { All deliveries conducted at } \\
\text { home }\end{array}$ & 3 & 55.0 & 45.0 & & & & \\
\hline \multicolumn{8}{|c|}{ Culture/religion dictate delivery } \\
\hline Health facility & 195 & 54.5 & 45.5 & \multirow[t]{2}{*}{0.4} & 0.2 & \multirow{2}{*}{-} & \multirow[t]{2}{*}{0.02} \\
\hline Home environment & 5 & 50.0 & 50.0 & & 0.9 & & \\
\hline
\end{tabular}

Table 3 presents findings on cultural and religious factors and reveals a significant relationship between cultural/religious dictates on delivery and uptake of skilled birth service. Women who perceived that health facility delivery was dictated by culture and religion were $60 \%$ less likely to receive optimal skilled birth service unlike their colleagues who thought otherwise (OR: $0.4 ; 95 \%$ CI: $0.2-0.9 ; \mathrm{p}=0.02)$. The rest of the other factors were not significantly associated with optimal skilled birth service

\section{Discussion:-}

The specific objectives were to determine the cultural and religious factors that influence uptake of skilled birth services in Lurambi sub-County. The correlation between cultural norms, values and beliefs and its influence on skilled birth deliveries is well documented in literature (Moyer, 2013; Dako-Gyeke et al,. 2013), but the study did not find a clear correlation of hospital delivery and religion as the high number of Christianity (97.5\%) as shown in figure 12 compared to Islam would be due to the fact that majority of the residence of Lurambi sub county are of Christian origin. Lurambi Sub County has two main ethnic origin Watsotso and Waidakho but the study found that majority of the women were from other ethnic origin (44.5\%) as illustrated in figure 11, this could be associated with the fact that Lurambi Sub County is cosmopolitan area as majority of the residence are from other areas. This may be in agreement with Studies that have demonstrated association between ethnicity and utilisation of skilled care (Van Malderen et al., 2013; Sakeah et al., 2014). A study carried out in Northern Ghana, found ethnicity as a predictor for utilisation of skilled birth attendance.

\section{Conclusion:-}

The study concludes that Culture and religion were less likely associated with determination of use of skilled birth services

\section{Recommendations:-}

1. The researcher recommends that sensitization of the elderly women and adolescent girls be done on importance of early access of antenatal clinic and hospital delivery through the community health volunteers.

2. The county government should make access to health facilities easier to mothers by availing ambulance services to transport mothers from the community to the facility.

3. The community to be sensitized to plan and have a community ambulance in which they own and can be sustained with the available resources.

\section{Declarations}

\section{Ethics Approval}

The study Ethical clearance was done bym Masinde Muliro University of Science and Technology Ethics Committee. Consent and approval were also obtained from Kakamega county director of heath Chair of the identified health facilities and the local administration in each of the sub counties. 


\section{Authors\& contributions}

Beatrice Mukabana and Victor Mukaka conceived, designed and performed the study. Micky Olutende Oloo analyzed the data. All authors read and approved the final manuscript.

\section{Disclaimer}

The findings and conclusions presented in this manuscript are those of the authors and do not necessarily reflect the official position of Masinde Muliro University.

\section{Acknowledgements:-}

We are grateful to the health facilities and healthcare professionals who granted permission to participate in this study, the county government of Kakamega and the facility managers.

\section{Reference:-}

1. Al-Mujtaba M.,Cornelius L.J.,Galadanci H., Erekaha S., Okundaye J. N., Adeyemi O. A., and Sam-Agudu N. A., (2016). Evaluating Religious Influences on the Utilization of Maternal Health Services among Muslim and Christian Women in North-Central Nigeria. BioMed Research International. Volume 2016, Article ID 3645415, http://dx.doi.org/10.1155/2016/3645415

2. Bourbonnais, N. (2013). Implementing Free Maternity Care in Kenya, Challenges, strategies and recommendation - KNCHR

3. Dako-Gyeke , Aikins, M, Aryeetey, R, Mccough, L \& Adongo PB 2013, "The influence of socio-cultural interpretations of pregnancy threats on health-seeking behaviour among pregnant women in urban Accra, Ghana", BMC Pregnancy and Childbirth, Vol.13, no. 211

4. Dzakpasu, S., Powell-Jackson, T., and Campbell O.M. (2013). Impact of user fees on policy maternal health service utilization and related health outcomes: A systematic review. Health and planning; 1-14. Doi:10.1093/heapol/czs 142

5. Esena, R. K., \& Sappor, M. M. (2013). Factors Associated with the utilization of skilled delivery services in the Ga East Municipality of Ghana Part 2: Barriers to skilled delivery. Int J Sci Tech Res, 2(8), 195-207

6. Ganle J. K. (2015). "Why Muslim women in Northern Ghana do not use skilled maternal healthcare services at health facilities: a qualitative study," BMC International Health and Human Rights, vol. 15, no. 1, article 10, 2015.

7. Hussen S. A., Tsegaye M., Argaw M. G., Andes K., Gilliard D., and del Rio C,(2014). "Spirituality, social capital and service: factors promoting resilience among Expert Patients living with HIV in Ethiopia," Global Public Health, vol. 9, no. 3, pp. 286-298, 2014.

8. KDHS, (2014). DHS Final Reports; survey: Kenya DHS King R., et al., (2015). Barriers and facilitators to accessing skilled birth attendants in Afar region, Ethiopia. Midwifery,31(5): p. 540-6. pmid:25745841

9. Kitui J, Lewis S, Davey G. (2013). Factors influencing place of delivery for women in Kenya: an analysis of the Kenya demographic and health survey, 2008/2009.. BMC Pregnancy Childbirth, 2013; 13: 40.

10. Markos M., Gobopamang L., Kannan N., Hadgu B. (2017). Individual, household and contextual factors associated with skilled delivery care in Ethiopia: Evidence from Ethiopian demographic and health surveys. https://doi.org/10.1371/journal.pone.0184688

11. Muckle, W., Sprague, A., \& Fergus, S. (2013). Barriers to access of maternity care in Kenya: a social perspective. J Obstet Gynaecol Can, 35(2), 125-130.

12. Sakeah, E, Doctor, HV, McCloskey, L, Bernstein, J, Yeboah-Antwi, K, Mills, S 2014, " Using the communitybased health planning an services program to promote skilled delivery in rural Ghana: socio-demographic factors that influence women utilization of skilled attendants at birth in Northern Ghana" BMC public health, Global health Vol. 14

13. UNAIDS, (2014). Gender Matters: Overcoming Gender-Related Barriers to Prevent New HIV Infections among Children and Keep their Mothers Alive, UNAIDS, Geneva, Switzerland.

14. World Health Organisation. (2014). Reproductive health indicators: guidelines for their generation, interpretation and analysis for global monitoring. URL: www.who.int/reproductivehealth/publications/rh_indicators/. Accessed 28th Sept_2014. 